\title{
Risk and severity of psoriasis vulgaris in relation to angiotensin II type I receptor gene polymorphism and metabolic syndrome
}

This article was published in the following Dove Press journal:

Clinical, Cosmetic and Investigational Dermatology

\author{
Mohamed Ibrahim EIGhareeb' \\ Mohamed Hamed Khater' \\ Ahmed Fakhr ${ }^{2}$ \\ Hanaa Abd-Elftah Khedr ${ }^{3}$ \\ 'Dermatology and Venereology \\ Department, Faculty of Medicine, Zagazig \\ University, Zagazig, Egypt; ${ }^{2}$ Microbiology, \\ Molecular Biology and Immunology \\ Department, Faculty of Medicine, Zagazig \\ University, Zagazig, Egypt; ${ }^{3}$ Dermatology \\ Department, Al Ahrar Hospital, Zagazig, \\ Egypt
}

Correspondence: Mohamed Ibrahim

EIGhareeb

Dermatology and Venereology

Department, Faculty of Medicine, Zagazig

University, Zagazig, Egypt

Tel +201092907455

Email moh_elghareeb@yahoo.com
Background: Psoriasis vulgaris is a chronic inflammatory and proliferative skin disease, characterized by the formation of itchy, erythematous skin patches or plaques. Patients with psoriasis are at an increased risk of developing metabolic syndrome, including obesity, hypertension, diabetes, and atherosclerosis. Recently, angiotensin II (Ang II) has been reported to be associated with the development of psoriasis. Ang II not only increases the blood pressure but is also a potent proinflammatory modulator and functions through interaction with angiotensin II type 1 receptor (AT1R). Moreover, it is hypothesized that the AT1R gene expression could be correlated with the severity of psoriasis and/or metabolic syndrome.

Aim: We examined the association of Ang II type 1 receptor (AT1R) A1166C gene polymorphisms and metabolic syndrome with the severity of psoriasis.

Patients and methods: The present case-control study included 25 patients with psoriasis vulgaris and 25 healthy subjects in Egypt. The psoriasis lesions in the patient group were assessed using the psoriasis area and severity index (PASI) score. The AT1R polymorphism A1166C (rs5186) was studied using restriction fragment length polymorphism (RFLP) and polymerase chain reaction (PCR) amplification of the gene from the whole blood sample in both groups. Serum lipid profile and blood sugar levels were assessed post $12 \mathrm{~h}$ and $8 \mathrm{~h}$ fasting, respectively, in both groups. The severity of metabolic syndrome was evaluated using the severity score.

Results: The results of the present study demonstrated that the AT1R A1166C gene polymorphisms increased the risk of developing psoriasis in the Egyptian population. We found that $70 \%$ of patients with AC genotype and $100 \%$ of patients CC genotype reported a PASI score $>20$ and were considered to be severe cases with a statistically significant difference as compared with patients with AA genotype $(p=0.003)$. In addition, a high statistically significant difference $(p=0.001)$ existed among AT1R genotypes with respect to the percentage of metabolic syndrome in psoriasis patients. Similarly, a statistically significant difference $(p=0.004)$ among AT1R genotypes with respect to metabolic score was found, with the highest level of score and percentage observed in patients with $\mathrm{CC}$ genotype than in patients with AC genotype. The lowest level was present among those with AA genotype.

Conclusion: Patients with psoriasis expressing the $\mathrm{C}$ allele of AT1R1166 are susceptible to developing metabolic syndrome and have higher PASI scores as compared with patients carrying the A allele.

Keywords: psoriasis, metabolic syndrome, angiotensin receptor, gene polymorphism

\section{Introduction}

Psoriasis is a chronic and systemic inflammatory skin disease that affects approximately $2-4 \%$ of the world population. ${ }^{1}$ It is associated with several 
cardio-metabolic co-morbidities, such as obesity, insulin resistance, dyslipidemia, and hypertension. ${ }^{2}$

Several studies have reported patients with psoriasis to be at a higher risk of developing cardiovascular co-morbidities and metabolic syndrome. Moreover, published data demonstrate a correlation between the severity of skin changes, cardiovascular co-morbidities, and features of metabolic syndrome in patients with psoriasis. One study reported a striking histological similarity between psoriasis plaques and atherosclerotic plaques. Both plaques have elevated levels of activated $\mathrm{T}$ helper 1 and $\mathrm{T}$ helper 17 cells that trigger inflammation in various tissues. $^{3}$

An individual is reported as having the metabolic syndrome if he/she has three or more of the following features: (I) waist circumference $\geq 102 \mathrm{~cm}$ in men, $\geq 88$ in women, (II) triglycerides $\geq 150 \mathrm{mg} / \mathrm{dL}$, (III) high-density lipoprotein cholesterol (HDL-C $<40 \mathrm{mg} / \mathrm{dL}$ in men, $<50 \mathrm{mg} / \mathrm{dL}$ in women (IV) blood pressure $\geq 130 / 85$, and (v) fasting glucose $>100 \mathrm{mg} / \mathrm{dL}$ or diagnosed diabetes. ${ }^{4}$

A study reported the involvement of tissue angiotensinconverting enzyme (ACE) in regulating the cutaneous inflammatory response by converting angiotensin I (Ang I) to angiotensin II (Ang II) and degrading the bradykinin and substance $\mathrm{P}$, both of which are strong mediators of inflammation. The lower ACE activity is associated with reduced degradation of kinins, which may be considered as one of the factors implicated in the development of psoriatic lesions. ${ }^{5}$

Most of the physiological and pathophysiological actions of Ang II are mediated through its interaction with angiotensin II type 1 receptor (AT1R). The quality/ quantity of AT1R gene expression is correlated with the severity of psoriasis and its complications, such as hypertension, heart disease, and oxidative stress. ${ }^{6}$

The $\mathrm{C}$ allele of the AT1R-A1166C may be considered a strong independent predictive factor of oxidative stress and inflammation. This also suggests that psoriasis patients carrying the $\mathrm{C}$ allele of AT1R1166 are more susceptible to developing cardiovascular diseases and myocardial infarction as compared with psoriasis patients carrying the A allele of AT1R1166. ${ }^{7}$

The frequency of the polymorphism involving the substitution of $\mathrm{C}$ for $\mathrm{A}$ at position 1166 in the 3'-untranslated region of A1166C significantly increased in hypertensive individuals. This association was most pronounced in those with an earlier onset of hypertension or more severe hypertension. ${ }^{8}$

\section{Patients and methods}

The present case-control study involved the following two groups: patients group that comprised 25 patients with psoriasis vulgaris and the control group consisting of 25 healthy, gender- and age-matched individuals. The study was conducted at the Dermatology and Venereology department outpatient clinic, Zagazig University Hospitals, Egypt. The AT1R genotyping was performed in the Molecular Biology laboratory of the Zagazig Scientific and Medical Research Center, Faculty of Medicine, Zagazig University. The study was approved by the Institutional Review Board (IRB) of the Faculty of Medicine, Zagazig University. Written informed consent to participate in the study was obtained from all participants. The work was conducted in accordance with The Code of Ethics of the World Medical Association (Declaration of Helsinki) for studies involving humans. The study did not involve any conflict of interest with respect to its conductance.

The patient group included patients with psoriasis of both genders and above 18 years of age, and suffering from different types of psoriasis vulgaris. The following patients with psoriasis were excluded from the study: (i) patients with erythrodermic, flexural, and pustular psoriasis, (ii) patients with drug-induced psoriasis, (iii) patients with severe renal, hepatic, and systemic diseases, (iv) patients with other chronic dermatological diseases, (v) patients with bleeding risks or blood diseases, and (vi) patients on anticoagulants or aspirin.

The psoriasis lesions in the patient group were assessed using the psoriasis area and severity index (PASI) score.

In order to study the association between psoriasis and metabolic syndrome, lipid profile, and blood sugar levels in the patients were assessed. At the genetic level, angiotensin II type 1 receptor polymorphism A1166C (rs5186) was studied using restriction fragment length polymorphism (RFLP) after gene amplification from the whole blood sample using polymerase chain reaction (PCR) in both the groups as follow:

Of venous blood, $4 \mathrm{~mL}$ was withdrawn under aseptic conditions from patients and controls after fasting for at least $12 \mathrm{~h}$ and divided into two tubes as follows:

- $2 \mathrm{~mL}$ of venous sample in sterile ethylenediaminetetraacetate (EDTA) tube was used for DNA Extraction. DNA samples were stored at $-20{ }^{\circ} \mathrm{C}$ to and used for performing PCR-RFLP of the A1166C gene. 
- $2 \mathrm{~mL}$ of clotted blood was centrifuged at $3000 \mathrm{rpm}$ for $5 \mathrm{~min}$. The serum was then separated and divided to determine the lipid profile and blood glucose levels. Total cholesterol, triglyceride, and HDL-cholesterol levels were also measured using a colorimetric method. The levels of low-density lipoprotein (LDL)-cholesterol were calculated according to the following formula: LDL-cholesterol $=$ total cholesterol $-($ very low-density lipoprotein [VLDL]-cholesterol + HDL-cholesterol) (Friedewald formula). ${ }^{9}$ The blood glucose level was calculated using an enzymatic coupled reaction. ${ }^{10}$

The metabolic syndrome severity was calculated using the metabolic syndrome severity score designed by the public health department of biostatistics of West Virginia University. ${ }^{11}$

\section{DNA analysis for determining angiotensin II type I receptor gene polymorphism by PCR-RFLP}

The PCR-RFLP was performed in the following five main steps:

1. Extraction of genomic DNA from peripheral blood leucocytes of EDTA anti-coagulated blood. ${ }^{12}$

2. Amplification of the extracted DNA according to the proposed protocol. ${ }^{13}$

3. Detection of PCR-amplified products using 1.5\% agarose gel electrophoresis containing ethidium bromide and visualized using the ultraviolet light (UV) trans-illumination.

4. Digestion of amplified products with a suitable restriction enzyme (Ddel restriction endonuclease enzyme).

5. Analysis of digested products by electrophoresis on $3 \%$ agarose gel containing ethidium bromide and band visualization using UV trans-illumination for determining A1166C genotypes.

For detection of $\mathrm{A} 1166 \mathrm{C}$ polymorphism of the angiotensin II receptor, two oligonucleotide primers were used for amplifying the corresponding DNA fragment by PCR. ${ }^{13}$

5`-AATGCTTGTAGCCAAAGTCACCT -3`(F)

5 -GGCTTTGCTTTGTCTTGTTG -3` (R)

The reaction was performed in a final volume of $25 \mu \mathrm{L}$ containing $30 \mathrm{pmol}$ of each primer, $0.1 \mathrm{mmol}$ of each deoxynucleoside triphosphate, $1 \mathrm{U}$ Taq DNA polymerase
(Qiagen, Germany), $50 \mathrm{mmol} / \mathrm{L} \mathrm{KCl}, 2.5 \mathrm{mmol} / \mathrm{L} \mathrm{MgCl}_{2}$, $10 \mathrm{mmol} / \mathrm{L}$ Tris- $\mathrm{HCl}(\mathrm{pH}=8.3)$, and $250 \mathrm{ng}$ of genomic DNA.

The PCR was carried out under the following conditions: Initial denaturation at $94{ }^{\circ} \mathrm{C}$ for $5 \mathrm{~min}$. This was followed by 40 cycles of denaturation at $94{ }^{\circ} \mathrm{C}$ for $30 \mathrm{sec}$, annealing at $57{ }^{\circ} \mathrm{C}$ for $30 \mathrm{sec}$, and extension at $72{ }^{\circ} \mathrm{C}$ for $1 \mathrm{~min}$ and $30 \mathrm{sec}$, and the final extension at $72{ }^{\circ} \mathrm{C}$ or 5 min.

The PCR fragments (856 bp) were digested with Dde1 restriction enzyme (Biolab, UK) for $16 \mathrm{~h}$ at $37^{\circ}$; the wildtype allele (A allele) has one Ddel cleavage site and was digested to 600 and $256 \mathrm{bp}$ fragments, whereas the mutant allele (C allele) has two Dde1 cleavage sites and the 256bp fragment was cleaved to 146 and $110 \mathrm{bp}$ fragments.

The digested samples were separated by electrophoresis on a $2 \%$ agarose gel for $1 \mathrm{~h}$ and visualized by ethidium bromide staining under UV trans-illumination.

\section{Detection of mutated allele bands in agarose gel using ultra-violet}

\section{tran-illumination}

Polymorphism in the AT1R gene at nucleotide 1166 (A1166C) was identified as follows: As shown in Figure 1, from left to right, lane 1 demonstrates the DNA ladder (100bp marker); lanes 2, 3, 4, 6, and 8 demonstrate 2 bands at $600 \mathrm{bp}$ and $256 \mathrm{bp}$ in homozygous wild type subjects (AA); lane 7 indicates 4 bands at $600 \mathrm{bp}, 256 \mathrm{bp}, 146 \mathrm{bp}$, and $110 \mathrm{bp}$ in heterozygous subjects (AC); lane 9 indicates bands at $600 \mathrm{bp}, 146 \mathrm{bp}$ and $110 \mathrm{bp}$ with polymorphic sites indicated by arrows in the homozygous subject (CC).

\section{Results}

The data collected in the present study were tabulated and analyzed using the SPSS version 16 software (SPSS Inc., ILL Company, Chicago). Categorical data are presented as numbers and percentages, whereas quantitative data are expressed as mean \pm standard deviation and as the range.

Patients with psoriasis were subdivided according to the PASI score (psoriasis area and severity index). Nine (36\%) patients had PASI $<10$ and reported mild psoriasis, whereas 8 (32\%) patients had PASI ranging from 10 to 20 and reported moderate psoriasis. Eight (32\%) patients with PASI $>20$ had severe psoriasis.

The severity of psoriasis among psoriasis patients detected by the PASI score ranged from 4 to 26 with a mean of $13.58 \pm 6.75$. 


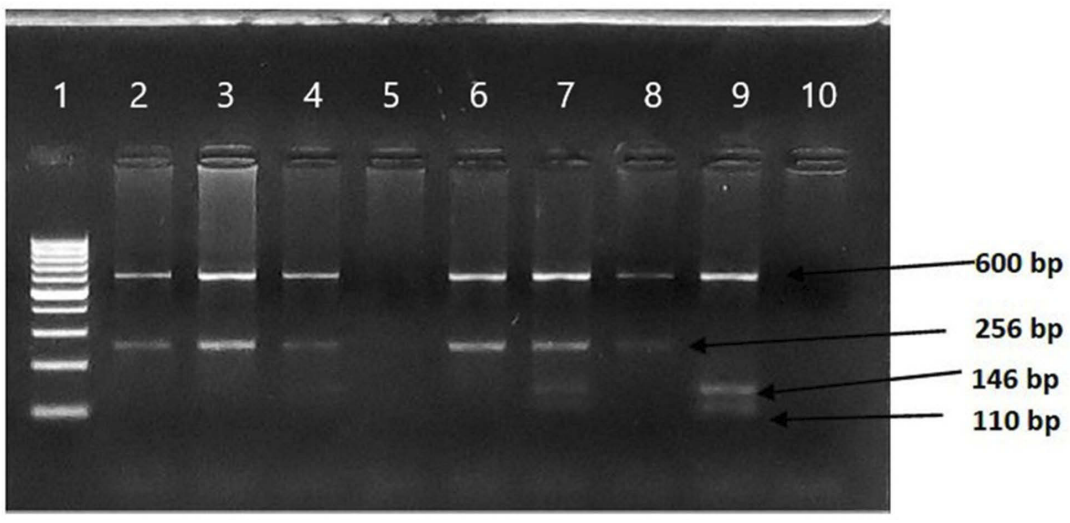

Figure I Restriction enzyme analysis of the ATIR gene (AII66C) polymorphism. AA, CC, and AC genotypes are shown.

There was a high statistically significant difference among both psoriasis patients and their controls with respect to waist circumference (WC), systolic blood pressure, diastolic blood pressure, total cholesterol, and triglyceride levels. However, no statistically significant difference was observed among psoriasis patients and their controls with respect to the fasting glucose levels (Table 1).

There was a statistically significant difference among psoriasis patients and their controls with respect to the metabolic score $(0.42 \pm 0.31$ among controls versus 0.72 \pm 0.59 among psoriasis patients) and metabolic percentage (higher among psoriasis patients with a mean of 70.3 $\pm 22.5 \%$ versus $53.9 \pm 23.3 \%$ among controls; Table 2 ).

We observed a higher percentage of AT1R gene polymorphism in both homozygotes (CC) and heterozygotes (AC) in the patient group as compared to the control group. However, this difference was not statistically significant (Table 3).

As regarding the PASI score of psoriasis patients, we found a high statistically significant difference among AT1R genotypes, with the highest level of PASI score

Table I Clinical and laboratory data among both studied groups

\begin{tabular}{|c|c|c|c|c|}
\hline \multirow[t]{2}{*}{ Variables } & \multicolumn{2}{|l|}{ Mean \pm SD } & \multirow[t]{2}{*}{$t$-test } & \multirow[t]{2}{*}{$P$-value } \\
\hline & Cases $=25$ & Controls $=25$ & & \\
\hline Waist circumference & $103.4 \pm 11.5$ & $91.4 \pm 9.2$ & 4.05 & $<0.00$ I** \\
\hline WC & $75-130$ & $79-110$ & & $\mathrm{H}$ \\
\hline Systolic blood pressure & $139.6 \pm 13.37$ & $112.2 \pm 9.15$ & 8.5 & $<0.00 I^{* *}$ \\
\hline SBP & $100-160$ & $80-150$ & & $\mathrm{H}$ \\
\hline Diastolic blood pressure & $90.4 \pm 9.24$ & $79.6 \pm 8.36$ & 5.71 & $<0.001^{* *}$ \\
\hline DBP & $65-100$ & $60-110$ & & $\mathrm{H}$ \\
\hline High density lipoprotein & $60.7 \pm 9.99$ & $40.7 \pm 6.58$ & 0.87 & $<0.001^{* *}$ \\
\hline HDL & $23-69$ & $30-72$ & & $\mathrm{H}$ \\
\hline Low density lipoprotein & $|14.4 \pm| 4 . \mid$ & $96.3 \pm 13.7$ & 4.69 & $<0.00 I^{* *}$ \\
\hline LDL & $85-140$ & $90-137$ & & $\mathrm{H}$ \\
\hline Total cholesterol & $138.4 \pm 14.12$ & $106.4 \pm 16.7$ & 7.3 & $<0.00 I^{* *}$ \\
\hline TC & $115-150$ & $120-160$ & & $\mathrm{H}$ \\
\hline Triglycerides & $\mid 63.9 \pm 79.1$ & $126.4 \pm 48.4$ & 2.03 & 0.04 \\
\hline TRG & $64-381$ & $68-254$ & & $S$ \\
\hline \multirow[t]{2}{*}{ Fasting blood Glucose } & $108.4 \pm 27.3$ & $111.95 \pm 43.22$ & 0.351 & 0.727 \\
\hline & 78-203 & $8 I-275$ & & NS \\
\hline
\end{tabular}

Note: ${ }^{* * P} P$-value $<0.00 \mathrm{I}$ is highly significant, NS: $P$-value $>0.05$ is not significant, $S: P$-value $>0.05$. 
Table 2 Assessment of metabolic syndrome among both studied groups

\begin{tabular}{|l|l|l|l|l|}
\hline \multirow{2}{*}{ Variables } & \multicolumn{2}{|l|}{ Mean \pm SD } & \multirow{2}{*}{ MW $^{\#}$} & \multirow{2}{*}{-value } \\
\cline { 2 - 4 } & Cases=25 & Controls=25 & & \\
\hline $\begin{array}{l}\text { Metabolic score } \\
\text { Range }\end{array}$ & $\begin{array}{l}0.72 \pm 0.59 \\
0.03-3.83\end{array}$ & $\begin{array}{l}0.42 \pm 0.31 \\
0.02-4.17\end{array}$ & 2.57 & $0.0 I^{*}$ \\
\hline $\begin{array}{l}\text { Metabolic percent } \\
\text { Range }\end{array}$ & $\begin{array}{llll}53.9 \pm 22.5 \\
17.1-100\end{array}$ & $\begin{array}{l}53.7 .7-100 \\
24.3\end{array}$ & 2.45 & $0.0 I^{*}$ \\
\hline
\end{tabular}

Note: $* P$-value $<0.05$ is significant. ${ }^{\# M a n n-W h i t n e y ~ t e s t ~ o f ~ n o n-p a r a m e t r i c ~ d a t a . ~}$

found in patients with CC genotype than in those with $\mathrm{AC}$ genotype. The lowest level was reported by patients with AA genotype.

It was found that $70 \%$ of patients with AC genotype and $100 \%$ of patients CC genotype were regarded as severe cases, with PASI score $>20$ and with a statistically significant difference as compared with patients with AA genotype.

Regarding the metabolic percentage of psoriasis patients, a statistically significant difference among AT1R genotypes was observed. Similarly, we observed a statistically significant difference among AT1R genotypes with respect to the metabolic score, with the highest level of score and percentage found in patients with CC genotype than in those with AC genotype. The lowest level was observed in patients with AA genotype (Table 4).

A high statistically significant positive correlation existed between the PASI score and both the metabolic scores.

\section{Discussion}

Recently, the severity of psoriasis has been reported to be associated with increased prevalence of metabolic syndrome. ${ }^{14}$ Metabolic syndrome encompasses a group of cardiovascular diseases and pathogenesis and outcomes of which overlap with that of psoriasis. These include abdominal obesity, hypertension, dyslipidemia, and insulin resistance.

Increased $\mathrm{WC}$ is one of the diagnostic criteria of metabolic syndrome. The present study revealed WC to be significantly higher in psoriasis patients $(p<0.001)$ in comparison to that in the control group. These results are similar to that obtained by previous studies by Gisondi et al $(2010)^{15}$ and Zindanc et al (2012) ${ }^{16}$

With respect to hypertension, our study revealed that both systolic and diastolic blood pressures were significantly higher in patients with psoriasis $(p<0.001)$ in comparison to that in the control group. This finding is in agreement with those obtained in the studies performed by Sommer et al (2006) ${ }^{17}$ and Nisa (2010). ${ }^{18}$

The present study revealed a statistically significant difference in the total cholesterol levels between the psoriasis patients and the control group ( $p>0.001)$. This finding is in agreement with the results obtained by Malbrias et al $(2006)^{19}$ and Banerjee et al $(2014)^{20}$ who observed significantly increased levels of cholesterol in psoriasis patients in comparison to controls. However, these results are contrary to those obtained by Uyanik et al $(2002)^{21}$ and Ahmed (2011) ${ }^{22}$ who found no significant difference in the total cholesterol levels between patients and controls.

Next, we noticed a significant increase in the triglyceride levels in psoriasis patients as compared to the levels in the control group $(p<0.05)$; this finding is in agreement with the results obtained by Akhyani et al (2007). ${ }^{23}$ On the contrary, no significant difference was observed in the triglyceride levels between patients and controls in the studies by Baja et al (2009) ${ }^{24}$ and Toker et al (2009). ${ }^{25}$

The present study found low levels of HDL in psoriasis patients; this finding was significantly different in comparison to the control $(p<0.001)$. The same was observed by Reynoso et al (2003). ${ }^{26}$ On the contrary, Akhyani et al $(2007)^{23}$ and Toker et al (2009) $)^{25}$ reported no significant difference in the HDL-C levels between the groups.

Table 3 Different genotype distribution of ATIR gene among both studied groups

\begin{tabular}{|c|c|c|c|c|c|c|}
\hline \multirow[t]{3}{*}{ Genotype } & \multicolumn{4}{|c|}{ Group } & \multirow[t]{3}{*}{$x^{2}$} & \multirow[t]{3}{*}{$P$-value } \\
\hline & \multicolumn{2}{|c|}{ Cases $(n=25)$} & \multicolumn{2}{|c|}{ Controls $(n=25)$} & & \\
\hline & $\mathbf{N}$ & $\%$ & $\mathbf{N}$ & $\%$ & & \\
\hline AA (no polymorphism) & 14 & 56 & 18 & 72 & 2.03 & 0.363 \\
\hline AC (heterozygote) & 10 & 40 & 7 & 28 & & (NS) \\
\hline CC (homozygote) & I & 4 & 0 & 0.0 & & \\
\hline
\end{tabular}


Table 4 Relation between the occurrence of metabolic syndrome among psoriasis patients and ATIR genotypes

\begin{tabular}{|c|c|c|c|c|c|}
\hline & \multicolumn{3}{|c|}{ AT IR genotype groups } & \multirow[t]{2}{*}{ KW } & \multirow[t]{2}{*}{$P$-value } \\
\hline & $\begin{array}{l}\text { AA } \\
(n=14)\end{array}$ & $\begin{array}{l}A C \\
(n=10)\end{array}$ & $\begin{array}{l}\text { CC } \\
(n=I)\end{array}$ & & \\
\hline \multicolumn{6}{|l|}{ Metabolic percent } \\
\hline Mean \pm SD & $54.1 \pm 23.5$ & $91.43 \pm 7.1$ & 97.2 & 14.52 & 0.001 \\
\hline Range & I7.|-89.5 & $76.4-100$ & - & & $(\mathrm{H})$ \\
\hline \multicolumn{6}{|l|}{ Metabolic score } \\
\hline Mean \pm SD & $0.53 \pm 0.35$ & $1.44 \pm 0.85$ & 3.83 & 11.72 & 0.004 \\
\hline Range & $0.03-1.18$ & $0.48-3.1$ & 一 & & $(\mathrm{S})$ \\
\hline
\end{tabular}

Note: Kruskal-Wallis test of non-parametric data, $\mathrm{H}: P$-value $\leq 0.00 \mathrm{I}$ is highly significant, $\mathrm{S}: P$-value $<0.05$ is significant.

The LDL-C levels in psoriasis patients were found to be significantly higher than in the control group ( $p>0.001)$; similar findings were noted by Baja et al (2009), ${ }^{24}$ whereas an Iranian study by Farshchian et al $(2007)^{27}$ reported no significant difference in the LDL-C levels between the two groups.

With respect to the fasting glucose levels, we found no significant difference among psoriasis patients and their controls. Also, Gisondi et al (2010) ${ }^{15}$ and Khungar et al (2013) ${ }^{28}$ found that levels of hyperglycemia were not significantly associated with the occurrence of psoriasis. Contrary to this, Pereira et al $(2011)^{29}$ reported a significantly higher prevalence of impaired glucose levels in psoriasis patients.

Our study showed a significant increase in the metabolic syndrome in psoriasis patients as compared to the controls. We found a positive correlation between the PASI score and the metabolic percentage among psoriasis patients $(p<0.001)$. The same results were obtained by Madanagobalane et al (2012), ${ }^{30}$ who found a correlation between the severity of psoriasis and metabolic syndrome. This finding confirmed the inflammatory skin changes caused by psoriasis to have a direct role in determining these risk factors.

Genetics play a critical role in predicting the susceptibility of individuals to psoriasis and metabolic diseases. For instance, the psoriasis susceptibility loci PSORS2, PSORS3, and PSORS4 have been reported to be associated with loci of susceptibility for disorders, such as diabetes mellitus type 2 , familial hyperlipidemia, and cardiovascular disorders. ${ }^{31}$

One of the complications experienced in psoriasis is oxidative stress, which causes lipid peroxidation, DNA modification, and inflammatory cytokine secretion, thereby exacerbating the disease. This condition could be correlated with the expression of AT1R gene. ${ }^{32,33}$
The $\mathrm{C}$ allele of the AT1R-A1166C may be considered a strong independent predictive factor of oxidative stress and inflammation. ${ }^{33}$

Our study reported a statistically significant difference among AT1R genotypes with respect to metabolic score and percentage, with the highest level of score and percentage found in patients with $\mathrm{CC}$ genotype than in those with AC genotype. The lowest level was present in patients with the AA genotype. These results are in agreement with those reported by Abdollahi et al (2005), ${ }^{34}$ indicating the involvement of ATR1 polymorphism in the pathogenesis of these clinical conditions. This is also supported by the findings reported by Palatini et al (2009), ${ }^{35}$ who found that the frequency of the metabolic syndrome was more common among patients with $\mathrm{CC}$ and AC genotypes.

The current study reported a higher percentage of AT1R gene in both $\mathrm{CC}$ and AC polymorphism in the patient group in comparison to the controls; however, these results were not statistically significant. The study demonstrated a high statistically significant difference among AT1R genotypes with respect to the PASI score of psoriasis cases, with the highest level of PASI score found in patients with the CC genotype than in those with the AC genotype, whereas the lowest level was present in patients with the AA genotype.

These results are in agreement with those obtained by Mohammadi et al (2016) ${ }^{33}$ who reported that the presence of C allele of AT1R was significantly increased in psoriasis patients in comparison to the levels in the controls. Moreover, the presence of the $\mathrm{C}$ allele increased the risk and severity of psoriasis, and psoriasis patients carrying the $\mathrm{C}$ allele of AT1R1166 were found to be susceptible to developing cardiovascular diseases and myocardial infarction as compared with psoriasis patients carrying the A 
allele of AT1R1166. This finding coincided with that of Tanhapour et al (2018) ${ }^{36}$ who showed an association of AT1R A1166C polymorphism and lipid profiles with psoriasis susceptibility, and that the concurrent presence of $\mathrm{C}$ allele of AT1R A1166C increased the risk of psoriasis.

Based on these findings, we believe that the current study is the first of its kind to demonstrate the association of AT1R A1166C polymorphism and lipid profiles with psoriasis susceptibility in Egypt.

\section{Conclusion}

Patients with psoriasis expressing the $\mathrm{C}$ allele of AT1R1166 are susceptible to developing metabolic syndrome and have higher PASI scores as compared with psoriasis patients carrying the A allele of AT1R1166.

\section{Disclosure}

The authors report no conflicts of interest in this work.

\section{References}

1. Fotiadou C, Lazaridou E, loannides D. Management of psoriasis in adolescence. Adolesc Health Med Ther. 2014;5:25. doi:10.2147/ AHMT.S36672

2. Sales R, Torres T. Psoriasis and metabolic syndrome. Acta Dermatovenerol Croat. 2014;22(3):169.

3. Wolska A, Michalsk-Jakabus M, Pietrzak A, et al. Metabolic syndrome in patients with psoriasis. Pol Merkur Lekarski. 2014;36 (213):215-219.

4. Grundy SM, Cleeman JI, Daniel SR, et al. Diagnosis and management of the metabolic syndrome : an American heart association national heart lung and blood institute scientific statement. circulation. 2005;112:2735-2752. doi:10.1161/CIRCULATIONAHA.105.16 9404

5. Scholzen TE, Stander S, Riemann H, et al. Modulation of cutaneous inflammation by angiotensin-converting enzyme. $J$ Immunol. 2003;170:3866-3873. doi:10.4049/jimmunol.170.7.3866

6. Rahimi Z, Rahimi Z, Aghaei A, et al. AT2R -1332 G: a polymorphism and its interaction with AT1R $1166 \mathrm{~A}: \mathrm{C}, \mathrm{ACE}$ I/D and MMP-9 $1562 \mathrm{C}$ : $\mathrm{T}$ polymorphisms: risk factors for susceptibility to preeclampsia. Gene. 2014;538:176-181. doi:10.1016/j.gene.2013.12.013

7. Yang K, Zhang F, Li F, et al. Angiotensin converting enzyme insertion/deletion polymorphism and susceptibility to psoriasis in a Chinese population. $J$ Renin Angiotensin Aldosterone Syst. 2014;15:39-43. doi:10.1177/1470320313494433

8. Kikuya M, Sugimoto K, Katsuya T, et al. A/C1166 gene polymorphism of the Angiotensin II type 1 receptor (AT1) and ambulatory blood pressure: the Ohasama study. Hypertens. 2003;26:141-145.

9. Artiss JD, Zak B. Measurement of cholesterol concentration In: Rifai $\mathrm{N}$, Warnick GR and Dominiczak MH, editor. Handbook of Lipoprotein Testing. Washington: AACC Press; 1997:99-114.

10. Trinder P. Determination of glucose in blood using glucose oxidase with an alternative oxygen acceptor. Ann Clin Biochem. 1969;6:24 27. doi: $10.1177 / 000456326900600108$

11. Soldatovic I, Vukovic R, Culafic D, et al. siMS score : simple method for quantifying metabolic syndrome. PLOS ONE. 2016;11(1): e0146143. doi:10.1371/journal.pone. 0146143

12. Trowsdale J. Genetic structure and function in MHC. Trends Genet. 1993;9:117-121. doi:10.1016/0168-9525(93)90205-V
13. Wu Z, chen $Z$, Logan OM, et al. Transparent, conductive, carbon nanotube films. Science. 2004;305(5688):1273-1276. doi:10.1126/ science. 1101243

14. Gelfand JM, Yeung H. Metabolic syndrome in patients with psoriatic disease. J Rheumatol Suppl. 2012;89:24-28. doi:10.3899/ jrheum. 120237

15. Gisondi P, Ferrazzi A, Girolomoni G. Metabolic comorbidities and psoriasis. Acta Dermatovenerol Croat. 2010;18(4):297-304.

16. Zindanc I, Albayrak O, Kavala M, et al. Prevalence of metabolic syndrome in patients with psoriasis. Sci World J. 2012;312463:1-5.

17. Sommer DM, Jenisch S, Suchan M, et al. Increased prevalence of metabolic syndrome in patients with moderate to severe psoriasis. Arch Dermatol Res. 2006;298(7):321-328. doi:10.1007/s00403-0060703-z

18. Nisa N, Qazi MA. Prevalence of metabolic syndrome in patients with psoriasis. Indian J Dermatol Venereol Leprol. 2010;76(6):662-665. doi:10.4103/0378-6323.72462

19. Malbrias L, Granath F, Hamsten A, et al. Psoriasis is associated with lipid abnormalities at the onset of skin disease. $J$ Am Acad Dermatol. 2006;54:614-621. doi:10.1016/j.jaad.2005.11.1079

20. Banerjee S, More U, Tilak MA, et al. Lipid alterations in psoriasis. Indian J Basic Appl Med Res. 2014;3(2):350-357.

21. Uyanik BS, Ari Z, Onur E, et al. Serum lipids and apolipoproteins in patients with psoriasis. Clin Chem Lab Med. 2002;40:65-68. doi:10.1515/CCLM.2002.013

22. Ahmed AA. Serum lipid profile in Psoriasis: a controlled study. Tikrit Med J. 2011;17(1):38-42.

23. Akhyani M, Ehsani A, Robati R, et al. The lipid profile in psoriasis: a controlled study. J Eur Acad Dermatol Venereol. 2007;21:13301332. doi:10.1111/jdv.2007.21.issue-10

24. Baja DR, Mahesar SM, Devrajani BR, et al. Lipid profile in patients with psoriasis presenting at Liaquat University Hospital Hyderabad. $J$ Pak Med Assoc. 2009;59(8):512-515.

25. Toker A, Kadi M, Yildirim AK, et al. Serum lipid profile paraoxonase and arylesterase activities in psoriasis. Cell Biochem Funct. 2009;27 (3):176-180. doi:10.1002/cbf. 1553

26. Reynoso DC, Martinez BR, Bustos SR, et al. Lipid profile, insulin secretion, and insulin sensitivity in psoriasis. J Am Acad Dermatol. 2003;48:882-885. doi:10.1067/mjd.2003.446

27. Farshchian M, Zamanian A, Farshichian M, et al. Serum lipid levels in Iranian patients with psoriasis. J Eur Assoc Deramatol Venereol. 2007;21:802-805. doi:10.1111/j.1468-3083.2006.02099.x

28. Khungar N, Gupta D, Ramesh V. Is psoriasis a new cutaneous marker for metabolic syndrome? A study in indian patients. Indian J Dermatol. 2013;58(4):313-314. doi:10.4103/0019-5154. 113958

29. Pereira R, Amladi S, Varthakavi P. A study of the prevalence of diabetes, insulin resistance, lipid abnormalities, and cardiovascular risk factors in patients with chronic plaque psoriasis. Indian $J$ Dermatol. 2011;56(5):520-526. doi:10.4103/0019-5154.87144

30. Madanagobalane S, Anandan S. Prevalence of metabolic syndrome in south indian patients with psoriasis vulgaris and the relation between disease severity and metabolic syndrome: a hospital based case control study. Indian J Dermatol. 2012;57(5):353-357. doi:10.4103/ 0019-5154.92669

31. Johann E, Gudjonsson T, Elder N, et al. Fitzpatrick's Dermatology in General Medicine. 7th. Vol. 1. McGraw-Hill; 2008:169-193.

32. Kadam DP, Suryakar AN, Ankush RD, et al. Role of oxidative stress in various stages of psoriasis. Indian J Clin Biochem. 2010;25:388392. doi:10.1007/s12291-010-0043-9

33. Mohammadi Y, Vaisi-Raygani A, Shakiba E, et al. Angiotensin II type 1 receptor A1166 C (rs5186) gene polymorphism increased risk and severity of psoriasis, contribution to oxidative stress, antioxidant statues, lipid peroxidation and correlation with vascular adhesion protein 1, preliminary report. J Eur Acad Dermatol Venereol. 2016;30:1395-1397. doi:10.1111/jdv.13652 
34. Abdollahi MR, Gaunt TR, Syddall HE, et al. Angiotensin II type I receptor gene polymorphism: anthropometric and metabolic syndrome traits. $J$ Med Genet. 2005;42(5):396-401. doi:10.1136/jmg.2004.024489

35. Palatini P, Ceolotto G, Dorigatti F, et al. Angiotensin II type 1 receptor gene polymorphism predicts development of hypertension and metabolic syndrome. Am J Hypertens. 2009;22(2):208-214. doi:10.1038/ajh.2008.319
36. Tanhapour M, Falahi B, Vaisi-Raygani A, et al. Angiotensin-converting enzyme insertion/deletion (rs106180) and angiotensin type 1 receptor A1166C (rs106165) genotypes and psoriasis: correlation with cellular immunity, lipid profile, and oxidative stress markers. $J$ Cell Biochem. 2018;10:1-7.

\section{Publish your work in this journal}

Clinical, Cosmetic and Investigational Dermatology is an international, peer-reviewed, open access, online journal that focuses on the latest clinical and experimental research in all aspects of skin disease and cosmetic interventions. This journal is indexed on CAS.
The manuscript management system is completely online and includes a very quick and fair peer-review system, which is all easy to use. Visit http://www.dovepress.com/testimonials.php to read real quotes from published authors. 